Article

\title{
Environmental Characteristics and Macrobenthic Community Structure of Yubu Island, a UNESCO-Designated Migratory Bird Sanctuary in the South Korea
}

\author{
Hye Seon Kim ${ }^{1}\left[\right.$ and Haryun Kim ${ }^{2, *}$ (i) \\ 1 Fundamental Research Division, National Marine Biodiversity Institute of Korea, Seocheon 33662, Korea; \\ hskim99@mabik.re.kr \\ 2 East Sea Research Institute, Korea Institute of Ocean Science \& Technology, Uljin 36315, Korea \\ * Correspondence: kharyun@kiost.ac.kr
}

Citation: Kim, H.S.; Kim, H. Environmental Characteristics and Macrobenthic Community Structure of Yubu Island, a UNESCO-Designated Migratory Bird Sanctuary in the South Korea. J. Mar. Sci. Eng. 2021, 9, 455. https://doi.org/10.3390/ jmse 9050455

Academic Editor: George Kontakiotis

Received: 25 March 2021

Accepted: 20 April 2021

Published: 22 April 2021

Publisher's Note: MDPI stays neutral with regard to jurisdictional claims in published maps and institutional affiliations.

Copyright: (c) 2021 by the authors. Licensee MDPI, Basel, Switzerland. This article is an open access article distributed under the terms and conditions of the Creative Commons Attribution (CC BY) license (https:// creativecommons.org/licenses/by/ $4.0 /)$.

\begin{abstract}
This study investigated the environmental characteristics and macrobenthic community structures of an intertidal flat located on Yubu Island in the western coastal area of the Yellow Sea of South Korea. The study site has been well known for the migratory bird protection designated by UNESCO. We collected the samples of surface and depth core sediments and macrobenthos from the unused saltern and the area surrounding it in July 2017. Our results demonstrated that the means of mud, total carbon, and total nitrogen contents were $50 \%, 0.35 \%$ and $0.05 \%$, respectively, and the origin of sediment composed of marine sources. The sedimentation rate ranged from 0.99 to $1.66 \mathrm{~cm} \mathrm{y}^{-1}$, which was higher than other tidal flats in the Yellow Sea. The result of a topographic analysis indicated that the area in the unused saltern was $289.489 \mathrm{~m}^{2}$, and the length and width were $625 \mathrm{~m}$ and $500 \mathrm{~m}$, respectively. A total of 13 species occurred with a mean density of 92 ind. $\mathrm{m}^{-2}$ and a mean biomass of $58.6 \mathrm{gWWt} \mathrm{m}^{-2}$. The Heteromastus filiformis $\left(23.1 \%, 21 \mathrm{ind} \mathrm{m}^{-2}\right)$ was the most dominant species, followed by Perinereis linea $\left(19.2 \%, 18\right.$ ind. $\left.\mathrm{m}^{-2}\right)$ and Tubuca arcuata $(17.3 \%$, 16 ind. $\mathrm{m}^{-2}$ ). Thus, this environmental information will help to establish policies to protect migratory birds in the future.
\end{abstract}

Keywords: intertidal flat; Yubu Island; environmental characteristics; macrobenthic community

\section{Introduction}

Yubu Island, located in Songrim-ri, Janghang-eup, Seocheon-gun, Chungcheongnamdo, is a small island with a tidal flat surrounded by a $4 \mathrm{~km}$ coastline and an area of $0.83 \mathrm{~km}^{2}, 13 \mathrm{~km}$ from the Geum River estuary in the western coastal areas of the Yellow Sea. The area is estimated to have significant changes in the topography and sediment composition of the tidal flat since it is affected by hydraulic changes due to the construction of artificial structures, such as the Geum River estuary dam and an industrial complex. Approximately 100 species of rare migratory birds come to rest on this island when traveling long distances to feed on the shellfish living in the sandy tidal flat. In recognition of this habitat characteristic, it was designated as the protected wetland area in 2008, the Ramsar wetland in 2009, and the East Asian-Australasian Flyway Partnership site (EAAF Network Site 101) in 2011. Among the major migratory birds on Yubu Island, there are 13 internationally endangered species listed on the IUCN Red List, such as the Eurasian oystercatcher and great knot. Additionally, 16 endangered species designated by the Ministry of Environment, such as the black-faced spoonbill (Platalea minor), and 9 kinds of natural monuments designated by the Cultural Heritage Administration, including the common kestrel, are known to inhabit the island [1].

Over the past 20 years, artificial structures such as the Gunjang National Industrial Complex and Saemangeum Seawall have been built around the coastal area near Yubu Island. The operation of the sluice gate of the Geum River estuary dam began in 1994, 
and fresh water is periodically discharged according to the rainfall to date [2]. In the Geum River estuary dam, where the flow of natural rivers is blocked, approximately 6 billion tons of fresh water are annually discharged through the temporary sluice gate opening [3]. Changes in sediment accumulation and ocean currents are being detected in the coastal area near Yubu Island since the training dike was built in the north and south for the protection of ports in and outside Gunsan in the early 1990s [4,5]. Thus, there is a need to study the environmental and ecological characteristics of Yubu Island to derive an appropriate management policy because it has been designated as a domestic and international migratory bird protection site.

To provide environmental data for the establishment of future ecological-based management policies in Yubu Island, this study traced the origin of organic matters through $\delta^{13} \mathrm{C}$ and $\delta^{15} \mathrm{~N}$ isotopes analyses and the physical and chemical characteristics of sediments. Additionally, we measured the annual sedimentation rate through the analysis of ${ }^{210} \mathrm{~Pb}$ and constructed the terrain data using drone images. We also conducted a survey on species composition and the habitat density of macrobenthos that are significantly affected by changes in the benthic environment. This study can provide essential data for long-term monitoring in future conservation and restoration projects on Yubu Island, as well as important information for analyzing environmental changes due to artificial structures near Yubu Island.

\section{Materials and Methods}

\subsection{Environmental Sample Collection and Analysis Method}

This study included a field survey in July 2017 for identifying the environmental and ecological features of the intertidal zone of the tidal flat, Yubu Island, located in Songrim-ri, Janghang-eup, Seocheon-gun, Chungcheongnam-do in the western coastal area of South Korea (Figure 1a). Sediments were collected from a total of eight study sites, including five sites inside the unused saltern with relatively stable terrain, where the saltern was present 50 years ago, and three sites around the unused saltern (Figure 1b). Inside the unused saltern, the sampling sites were selected in an $\mathrm{X}$ shape on the square topography in order to reflect the characteristics of the region evenly. The outside of the unused saltern was investigated by designing the sites at horizontal intervals (Figure 1b).

The ground temperature was measured at all eight sites using a geo-thermometer in the study area. In order to explore the characteristics of seawater, the electrical conductivity, water temperature, salinity, and $\mathrm{pH}$ of surface seawater were measured through a portable multi-water quality meter (YSI 650 MSD) in the bay where nearby seawater flows. Surface sediment samples were collected using a small core (diameter $10 \mathrm{~cm}$, depth $5 \mathrm{~cm}$ ), and they were stored on ice and transferred to the laboratory. The laboratory analysis of the surface sample was performed to provide physical data. Water content, loss on ignition, mud, total carbon/total nitrogen (TC/TN) contents, and $\delta^{13} \mathrm{C} / \delta^{15} \mathrm{~N}$ values were measured.

Water content and loss on ignition of the sediment samples were measured using the gravimetric method in accordance with the standard method for the examination of marine environments [6]. A certain amount of sediment samples was completely dried or ignited at $110^{\circ} \mathrm{C}(24 \mathrm{~h})$ and $550^{\circ} \mathrm{C}(2 \mathrm{~h})$ using an oven and furnace and then calculated using the difference in weight before and after. For mud content, Stoke's method was used to remove the organic matter in $20 \mathrm{~g}$ of the sample with hydrogen peroxide, and then mud sediments were separated by sifting through a $62.5 \mu \mathrm{m}$ diameter sieve. The sediment particles were categorized according to their diameter and separated using a Calgon solution, and the weight was measured. The TC and TN contents were measured using a high-temperature combustion method. For the TC measurement, inorganic carbon was removed with hydrochloric acid, and the total amount was measured using carbon dioxide $\left(\mathrm{CO}_{2}\right)$ and nitrogen gas $\left(\mathrm{N}_{2}\right)$ discharged after high heat combustion at $1000-1100{ }^{\circ} \mathrm{C}$ using an element analyzer (EA; Organic Elemental Analyzer, Elemantar, Germany). Regarding $\delta^{13} \mathrm{C} / \delta^{15} \mathrm{~N}$ isotope values, $\mathrm{CO}_{2}$ and $\mathrm{N}_{2}$ obtained after the thermal combustion of organic matter through an EA were measured using an EA-IRMS (Elemental Analyzer Isotope Ratio 
Mass Spectrometry; Isoprime, Germany). The values were expressed through the following formulas using reference materials $\left({ }^{13} \mathrm{C}\right.$; PDB, PeeDee Belmnnite, ${ }^{15} \mathrm{~N}$; atmospheric $\mathrm{N}_{2}$ ):

$$
\begin{aligned}
\delta^{13} \mathrm{C} & =\left[\mathrm{R}_{\text {sample }} / \mathrm{R}_{\text {standard }}\right] \times 1000(\% \mathrm{o}) \\
\delta^{15} \mathrm{~N} & =\left[\mathrm{R}_{\text {sample }} / \mathrm{R}_{\text {standard }}\right] \times 1000(\% \mathrm{o})
\end{aligned}
$$

(a)

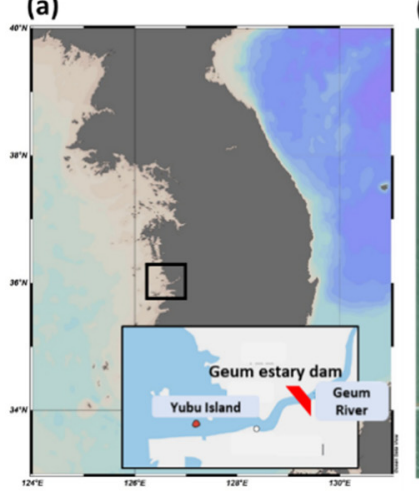

(b)

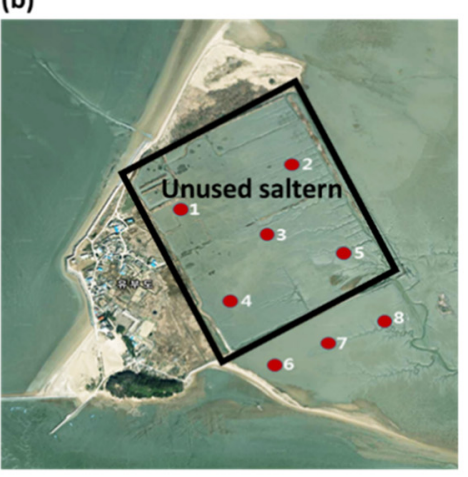

(c)

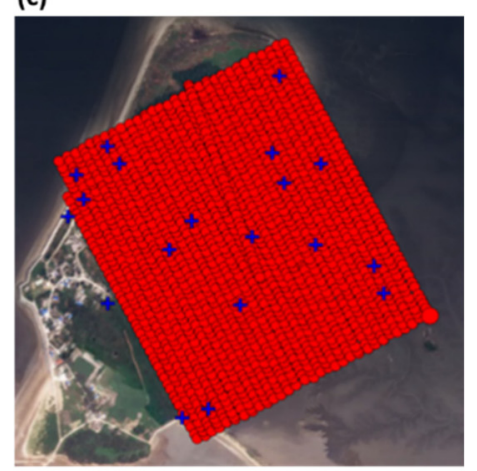

Figure 1. (a) location of Yubu Island tidal flat off the western coastal area of the Yellow Sea in the South Korea; (b) sampling sites; (c) the locations of GCP (blue x signal) and points of drone photos (red dots).

\subsection{Collection of Depth Core and Analysis of Sedimentation Rate}

To measure the sedimentation rate of Yubu Island, sediments were collected from the surface to a depth of $40 \mathrm{~cm}$ by using a $5 \mathrm{~cm}$ diameter passive vertical core. The samples were moved to the laboratory while maintaining a vertical shape in an acrylic cylinder mounted in the depth core. For analysis of ${ }^{210} \mathrm{~Pb}$ for dating, the core samples were freeze-dried after being subdivided into 2 -cm segments, pulverized into a powder form, and stored at room temperature until the analysis. To calculate the sedimentation rate, ${ }^{210} \mathrm{Po}$ was measured using an alpha-ray isotope analyzer after separating and concentrating the sediment's Po. In the collected sample, sufficient time was elapsed for ${ }^{210} \mathrm{Po}(\mathrm{t} 1 / 2=138.3$ day) and ${ }^{210} \mathrm{~Pb}\left(\mathrm{t} 1 / 2=22.3\right.$ year) to reach equilibrium. Thus, the measured radioactivity of ${ }^{210} \mathrm{Po}$ is generated by the parent nuclide, ${ }^{210} \mathrm{~Pb}$, and the radioactivity of ${ }^{210} \mathrm{Po}$ becomes ${ }^{210} \mathrm{~Pb}$. The value of the section, in which there is no vertical change in radioactivity from the total radioactivity of ${ }^{210} \mathrm{~Pb}$ calculated, is the radioactivity generated by the decay of the parent nuclide, ${ }^{226} \mathrm{Ra}$; thus, excess radioactivity of ${ }^{210} \mathrm{~Pb}$ can be identified. For estimating the sedimentation rate, the distribution of ${ }^{210} \mathrm{~Pb}_{\mathrm{ex}}$ (excess radioactive lead) according to the depth of the core was calculated, and the sedimentation rate was calculated by using the slope of the linear regression equation [7].

\subsection{The Survey of Topographic Map}

In order to understand the topographical characteristics of the Yubu Island habitat, drone images were taken twice in July 2017, and a three-dimensional natural topographic map of the unused saltern was created. Photos of the unused saltern area of the tidal flat of Yubu Island were taken by a drone at an altitude of $60 \mathrm{~m}$ for the $567,846 \mathrm{~m}^{2}$ area. The drone flew approximately $30 \mathrm{~km}$ for $90 \mathrm{~min}$ and took 1623 photos (Table 1). Drone shooting took place when the subject area was completely exposed at low tide. For altitude and location correction, GCP (Ground Control Points) was installed, and precise surveying was performed using GPS (Virtual reference station) (Figure 1c). Photos acquired using the drone were edited using Pix4D [8]. The color or luminosity of the photos varied depending on the weather conditions (solar radiation, angle of light, fog, and cloud movement) when it was taken; however, the shape of the terrain is known to have no effect on the location information. An additional 3D realization photo was simultaneously produced to provide additional information on the structure and shape of the terrain. 
Table 1. Information on the drone photography taken in the Yubu Island tidal flat in the western coastal area of South Korea.

\begin{tabular}{|c|c|c|c|c|c|c|c|}
\hline Altitude & Area & $\begin{array}{c}\text { Drone } \\
\text { Flying } \\
\text { Distance }\end{array}$ & $\begin{array}{c}\text { Drone } \\
\text { Running } \\
\text { Time }\end{array}$ & GCP & Pictures & Resolution & $\begin{array}{c}\text { Photo } \\
\text { Recovery } \\
\text { Rate }\end{array}$ \\
\hline $60 \mathrm{~m}$ & $567,846 \mathrm{~m}^{2}$ & $30 \mathrm{~km}$ & $90 \mathrm{~min}$ & 19 & 1623 & $2.60 \mathrm{~cm} \mathrm{pixel}^{-1}$ & $98 \%$ \\
\hline
\end{tabular}

\subsection{Benthos Collection and Analysis Method}

For benthos collection, sediments were collected three times using a can core (collection area: $0.024 \mathrm{~m}^{2}$ ) for each site. The collected sediment and benthos were separated at the site using a sieve with a mesh size of $1.0 \mathrm{~mm}$, fixed with $10 \%$ formalin, and transported to the laboratory. Macro-benthos transported to the laboratory were washed with fresh water to remove formalin and then sorted by taxa. The selected macro-benthos was identified and counted up to the species level using optical and dissecting microscopes. The habitat density was calculated by measuring the number of individuals per unit area $\left(\mathrm{m}^{2}\right)$. Additionally, the biomass (wet weight) of each species was measured up to $0.001 \mathrm{~g}$ using an electronic balance.

\subsection{Data Analysis}

For environmental data analysis, the mean value was calculated for the eight sites in the unused saltern and outside the unused salter. To compare the characteristics of the benthic invertebrate community, the diversity index [9], richness index [10], evenness index [11], and dominance index [12] were calculated for each site using the number of each population collected during the investigation period. Each index was calculated using the following equations:

Diversity index: $\mathrm{H}^{\prime}=-\Sigma \mathrm{P}_{\mathrm{i}} \times \ln \left(\mathrm{P}_{\mathrm{i}}\right)[9]$

$P_{\mathrm{i}}$ : Share of the $i$ th species

Richness index: $\mathrm{R}=(\mathrm{S}-1) / \ln (\mathrm{N})[10]$

$\mathrm{S}$ : Number of species

$\mathrm{N}$ : Total number of population

Evenness index: $\mathrm{J}=\mathrm{H}^{\prime} / \ln (\mathrm{S})[11]$

Dominance index: $\mathrm{D}=\left(\mathrm{Y}_{1}+\mathrm{Y}_{2}\right) / \mathrm{Y}[12]$

$\mathrm{Y}$ : Total number of population

$\mathrm{Y}_{1}$ : Population of the first dominant species

$\mathrm{Y}_{2}$ : Population of the second dominant species

Here, $P_{i}$ represents the percentage that the $i_{\text {th }}$ species occupies in the total population; $\mathrm{S}$ is the total number of species observed; $\mathrm{N}$ is the total number of present population.

\section{Results and Discussion}

\subsection{Physical Characteristics of Sediments}

The dissolved oxygen in the seawater near the tidal flat of Yubu Island was $6.7 \mathrm{mg} \mathrm{L}^{-1}$, and the $\mathrm{pH}$ was 8.2. The surface sediment temperature of the eight tidal flat sites of Yubu Island ranged from $27.1{ }^{\circ} \mathrm{C}$ to $28.0^{\circ} \mathrm{C}\left(27.53 \pm 0.38^{\circ} \mathrm{C}\right)$, a somewhat high temperature for summer, and there were no distinct differences among the regional sites.

We measured water content, loss on ignition, the contents, ratios and isotopic values for TC and TN, and mud content to investigate the characteristic of the surface sediment, and the data's average is described in Table 2 and Table S1. Interestingly, the mud content was generally low (33.5-66.2\%; mean value $50.4 \pm 3.4 \%$; Table 2 ). This would suggest that the particle structure in the sand would be high. It had a relatively lower value than the mud content in the Boryeong tidal flat (Ocheon/Hakseong area), Chungcheongnam-do (mean value of Ocheon area $72.4 \pm 3.4, n=18$; mean value of Hakseong area $68.8 \pm 3.8$, $n=18$ ) [13], and thus, it was expected to reveal the shape of the sandy tidal-flat of Yubu Island. However, the mud content of Yubu Island was higher than the estuary of the Geum 
River, where it was about twice as high as the mud content in the entire area of the Geum River estuary [13].

Table 2. Environmental characteristics of the Yubu Island tidal flat in the western coastal area of South Korea.

\begin{tabular}{ccccccccc}
\hline & $\begin{array}{c}\text { Water } \\
\text { Content }\end{array}$ & $\begin{array}{c}\text { Loss on } \\
\text { Ignition }\end{array}$ & $\begin{array}{c}\text { Total } \\
\text { Nitrogen }\end{array}$ & $\begin{array}{c}\text { Total } \\
\text { Carbon }\end{array}$ & $\begin{array}{c}\text { C:N } \\
\text { Ratio }\end{array}$ & $\begin{array}{c}\text { Mud } \\
\text { Content }\end{array}$ & $\boldsymbol{\delta}^{\mathbf{1 3}} \mathbf{C}$ & $\boldsymbol{\delta}^{\mathbf{1 5}} \mathbf{N}$ \\
\hline $\mathbf{( \% )}$ & $\mathbf{( \% )}$ & $\mathbf{( \% )}$ & $\mathbf{( \% )}$ & & $\mathbf{( \% )}$ & $\mathbf{( \% )}$ & $\mathbf{( \% )}$ \\
\hline Mean & 19.9 & 2.89 & 0.05 & 0.35 & 6.8 & 50.4 & -20.64 & 4.01 \\
SD & 0.7 & 0.18 & 0 & 0.04 & 0.8 & 3.4 & 0.19 & 0.36 \\
\hline
\end{tabular}

The carbon isotope value in organic matter $\left(\delta^{13} \mathrm{C}\right)$ can provide information on the origin of the organic matter because it differs depending on the biological process. For example, it is used to determine the origin of organic matter by using the characteristic that the $\delta^{13} \mathrm{C}$ value of phytoplankton in land plants and oceans differs because the degree of isotope classification is different during photosynthesis [14]. In the case of terrestrial organic matter formed by the $\mathrm{C} 3$ photosynthetic pathway from $\mathrm{CO}_{2}$ in the atmosphere, $\delta^{13} \mathrm{C}$ ranged between -21 and $-32 \%$ [15], while phytoplankton represents a $\delta^{13} \mathrm{C}$ of -26 to $-16 \%$ [16]. Along with the $\delta^{13} \mathrm{C}$, the total carbon/total nitrogen ratio (TC/TN) is used to discriminate between terrestrial and marine organic matters. If the ratio of TC/TN in organic matter is $>12$, it indicates terrestrial origin, and if it is $5-12$, it indicates a marine source [17]. In this study, the mean values of $\delta^{13} \mathrm{C}$ and $\delta^{15} \mathrm{~N}$ were about $-20.64 \pm 0.19 \%$ and $4.01 \pm 0.36 \%$ (Table 2), and the mean value of TC/TN ratio was 6.8 (Table 2). This implies that most of the organic matters are composed of marine sources in sediments of the unused saltern in Yubu Island and the outskirts (Figure 2). The $\delta^{15} \mathrm{~N}$ value was also close to the mean value of $5 \%$ of the oceanic water system [18].

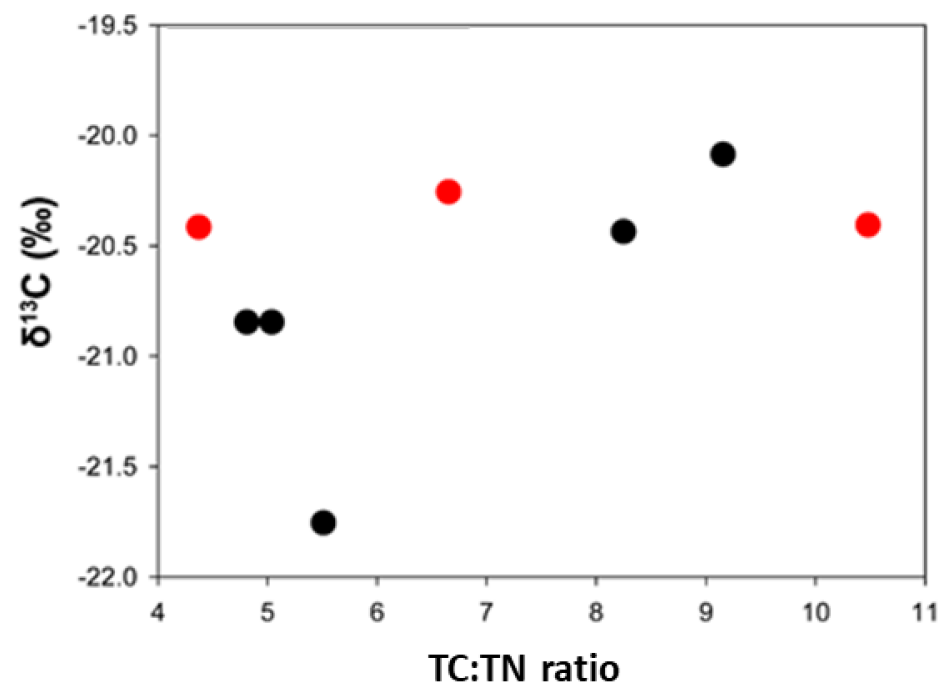

Figure 2. The correlation between the ratios of total carbon to total nitrogen and $\delta^{13} \mathrm{C}$ values in the sediments of the tidal flat of Yubu Island in the western coastal area of the Yellow Sea in South Korea. The red and black circles represent the unused saltern and southern tidal flats, respectively.

The sedimentation rate was measured by collecting each depth core from the unused saltern and the southern area of Yubu Island outside the unused saltern. As a result, in the unused saltern, about $0.99 \mathrm{~cm} \mathrm{yr}^{-1}$ was calculated, and the southern tidal-flat had a higher sedimentation rate of about $1.66 \mathrm{~cm} \mathrm{yr}^{-1}$ (Figure 3). The sedimentation rate in Yubu Island was high compared to the value of $0.2-0.8 \mathrm{~cm} \mathrm{yr}^{-1}$ in the tidal flat of Namyang Bay on the west coast [19]. Accordingly, an in-depth study is needed on the possibility of increasing 
the sedimentation rate of Yubu Island due to the construction of artificial structures in the estuary of Geum River and nearby sea areas in the future.

(a)

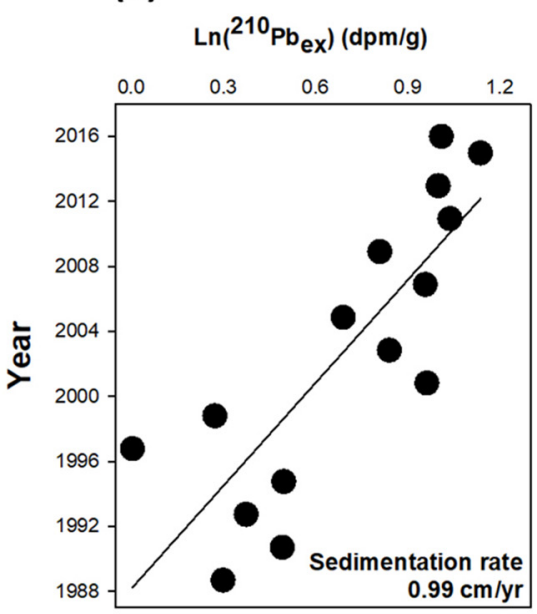

(b)

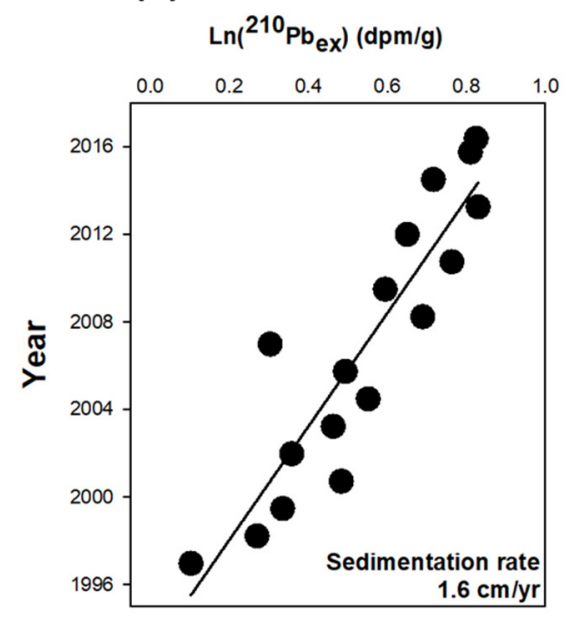

Figure 3. Sedimentation rates of the unused saltern (a) and the southern tidal flat (b) on Yubu Island in the western coastal area of the Yellow Sea in South Korea.

\subsection{Characteristics of Topography}

The area and perimeter of the unused saltern were measured using an orthophoto produced by drone photogrammetry. It was found to be approximately $289.489 \mathrm{~m}^{2}$, the length of the long axis in the north-south direction was about $628 \mathrm{~m}$, and the length of the short axis in the east-west direction was about $500 \mathrm{~m}$ (Figure 4a). As the southeastern unused saltern bank collapsed, the length of the part where seawater flow is estimated to be approximately $30 \mathrm{~m}$. As a result of the topographical photograph, an embankment where a plant community is developed was observed in the northwest of the unused saltern (Figure 5b), and in the southwest corner, embankment and seawater passage were developed (Figure 5c). In the southeast area, evidence of the loss of some embankments was observed (Figure 5d). Since a considerable amount of forest was developed behind the northeast embankment, terrestrialization was observed (Figure 5d). The size of the forest that makes up the community in the north could be estimated through the threedimensional topographic map, and the size of the plant community developed in the western region was also observed (Figure $4 b, c$ ).

As a result of the preliminary research on the Yubu Island topography, changes in the topography and the marine environment around Yubu Island were detected due to the construction of artificial structures built nearby. In particular, the currents around Yubu Island have been greatly weakened due to the construction of the northern embankment and the northern breakwater, and thus, the connection of the small islands around the Yubu Island, which were separated in the past, was [2,3]. As the Saemangeum 4 seawall construction was completed, the currents in the north-south direction became stronger than those in the east-west direction, and the flow of ocean currents entering around Yubu Island weakened. Accordingly, the development of the sedimentary environment near Yubu Island was observed. This could be attributed to the effect of the high sedimentation rate of Yubu Island compared to other regions, as observed in the sedimentation rate results of this study. In particular, there has been a study that found the phenomenon of erosion in southeast Yubu Island as the depth of the water deepened due to the construction and dredging of the training dikes in the south and the hydrogate effect of the Geum River estuary. The amplitude of individual tidal components influencing tidal constituent increases due to the operation of the estuary embankment [2]. Therefore, the collapse of the southeast embankment of unused saltern revealed in the drone image could be 
interpreted as an indirect result of the construction of the training dike near Yubu Island and the hydrogate operation of the Geum River estuary in this study.
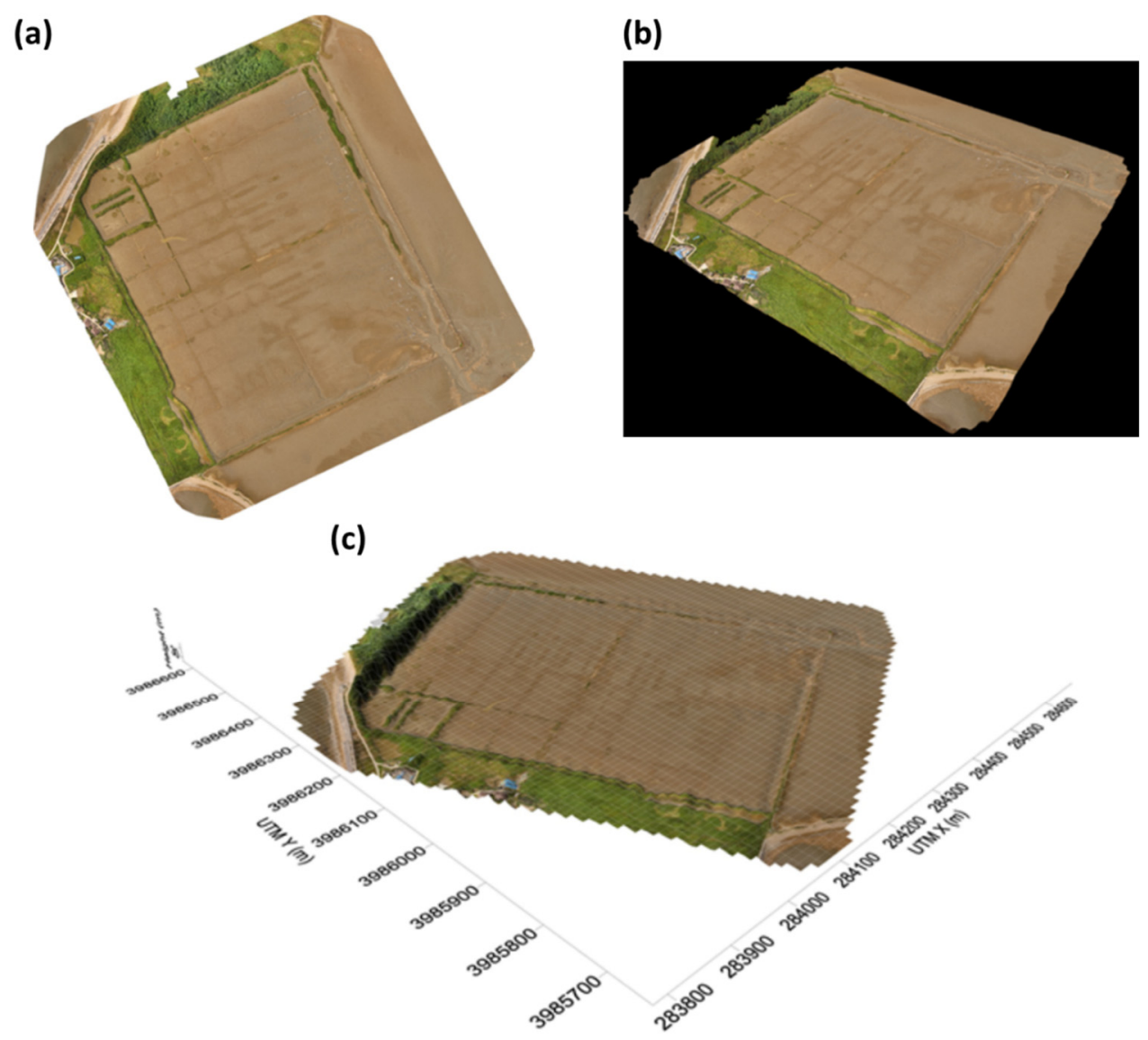

Figure 4. The drone photos: (a) the 3D image; (b) topographic map; and (c) the unused saltern area of the tidal flat in Yubu Island using a DEM (Digital elevation model).

(a)

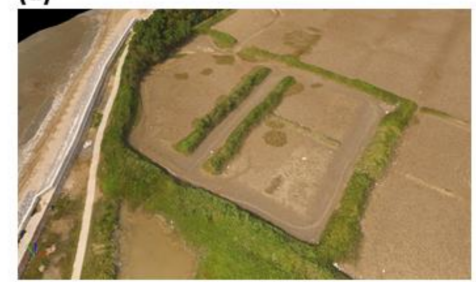

(c)

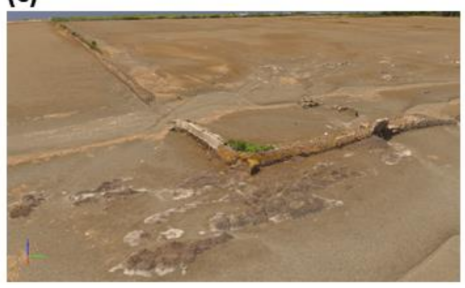

(b)

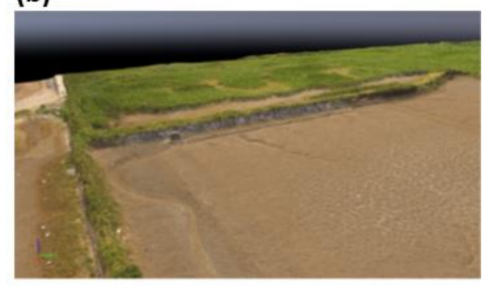

(d)

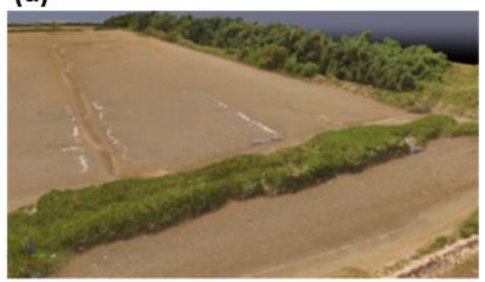

Figure 5. Northwestern embankment where the plant communities developed (a); the southwestern embankment and seawater passage (b); the destroyed southwestern embankment (c); the destroyed southeastern embankment of the unused saltern in the tidal flat of Yubu Island (d).

\subsection{Distribution Status of Macrobenthos}

The composition and abundance of macrobenthos, which plays a role in the energy flow and carbon cycle of the tidal flat ecosystem as a secondary producer and food source 
for predators, are representative biota that shows the health of the environment in which they live $[20,21]$. In particular, benthos is very sensitive to the direct impact of environmental changes and pollution caused by human activities because their habitat, such as the sedimentary environment, directly receives the pollutions and is affected by physical disturbance. They are one of the representative marine organisms that can indicate environmental vulnerability [22]. Accordingly, studies on the structure and function of the ecosystem have been actively conducted by examining the factors that change the community structure and diversity of macroinvertebrates in various studies [22].

The total of macrobenthos that appeared around the unused saltern of Yubu Island during this study was 13 species. The mean density was 92 ind. $\mathrm{m}^{-2}$, and the biomass was $58.6 \mathrm{~g} \mathrm{~m}^{-2}$. In terms of the taxonomic group, 1 mollusk, 6 arthropods, 5 annelids, and 1 nemertea appeared (Table 3). In terms of the mean density, it was 5 mollusks $\mathrm{m}^{-2}$, 39 arthropods $\mathrm{m}^{-2}, 44$ annelids $\mathrm{m}^{-2}$, and 4 nemertea $\mathrm{m}^{-2}$ (Table 3). The biomass was $0.1 \mathrm{~g} \mathrm{~m}^{-2}$ for mollusks, $5.5 \mathrm{~g} \mathrm{~m}^{-2}$ for arthropods, $53.0 \mathrm{~g} \mathrm{~m}^{-2}$ for annelids, and $0.03 \mathrm{~g} \mathrm{~m}^{-2}$ for nemertea. Although the density was similar between arthropods and annelids, the biomass of arthropods was 10 times higher than that of annelids. In a study conducted in Hakseong and Boryeong, Chungnam, a total of 79 species of macrobenthos were observed in one of the tidal flats on the west coast, and the mean density was 611 ind. $\mathrm{m}^{-2}$, which was higher than that of the tidal flat of Yubu Island [13]. The biomass was $64.1 \mathrm{~g} \mathrm{~m}^{-2}$, which was higher than the biomass of this study [13]. This can be interpreted as the result of the topographical difference between the unused saltern of Yubu Island and the tidal flat of the Hakseong and Boryeong. The tidal flat of Hakseong and Boryeong is a tidal flat formed in direct contact with the Yellow Sea, and the seawater freely flows [13]. The organic matter and mud content are higher than that of Yubu Island, making it a good environment for lugworm to inhabit. Conversely, the unused saltern of Yubu Island is facing the estuary dam of the Geum River and is likely to be disturbed by currents that are disconnected from the freshwater to coastal areas. Further, the possibility that the embankment formed during the use of saltern in the past and the forest and vegetation surrounding the embankment have restricted the free movement of tidal flat organisms cannot be excluded.

Table 3. Information on the macrobenthic species community collected from the tidal flat of Yubu Island in the western coastal area of South Korea.

\begin{tabular}{cccc}
\hline Taxon & $\begin{array}{c}\text { Total Species } \\
\text { Number }\end{array}$ & $\begin{array}{c}\text { Mean Density } \\
\text { (ind. } \mathbf{~ m}^{-2} \text { ) }\end{array}$ & $\begin{array}{c}\text { Mean Biomass } \\
\left(\mathbf{g ~ m}^{-2}\right)\end{array}$ \\
\hline Mollusca & 1 & 5 & 0.1 \\
Polychaeta & 5 & 44 & 5.5 \\
Crustacea & 6 & 39 & 53.0 \\
Nemertea & 1 & 4 & 0.03 \\
Total & 13 & 92 & 58.6 \\
\hline
\end{tabular}

Looking at the three most common benthos collected (Table 4), Heteromastus filiformis, an annelid with a mean density of 21 ind. $\mathrm{m}^{-2}(23.1 \%)$, was dominant, followed by Perinereis linea, an annelid with a mean density of 18 ind. $\mathrm{m}^{-2}(19.2 \%)$, and Tubuca arcuata, which is an arthropod with a mean density of 16 ind. $\mathrm{m}^{-2}(17.3 \%)$ (Table 4$)$. Heteromastus filiformis is a representative macrobenthic species living in the tidal flats of the southwestern coast of South Korea. It is known to primarily inhabit intertidal zones with high mud content [22]. In particular, Heteromastus filiformis is considered a representative pollutant indicator species living in organically polluted tidal flats in South Korea and abroad [23-25], and in particular, high habitat densities have been reported in environments with high organic matter contents [22]. The taxonomic record for Heteromastus filiformis was first introduced by domestic researchers in 2016, and research on cryptic species within this species population is currently being carried out [26]. 
Table 4. Dominant species of macrobenthos collected from the tidal flat of the Yubu Island in the western coastal area of South Korea.

\begin{tabular}{ccccc}
\hline Taxa & Species Name & $\begin{array}{c}\text { Mean Density } \\
\text { (ind. } \mathbf{~ m}^{-\mathbf{2}}\end{array}$ & $\begin{array}{c}\text { Percentage } \\
\mathbf{( \% )}\end{array}$ & Frequency \\
\hline \multirow{2}{*}{ Polychaeta } & Heteromastus filiformis & 21 & 23.1 & 5 \\
& Perinereis linea & 18 & 19.2 & 5 \\
Arthropoda & Tubuca arcuata & 16 & 17.3 & 5 \\
Mollusca & Macrophthalmus japonicus & 14 & 15.4 & 5 \\
& Assiminea sp. & 6 & 5.8 & 2 \\
\hline
\end{tabular}

Perinereis linea, a subdominant species, is an annelid that inhabits intertidal flats on the west coast of South Korea. Heteromastus filiformis and Perinereis linea have rounded nodes regularly connected to the body, and each node has a characteristic hairy leg called setae. Polychaetes, annelids with this shape, have the largest number of species and populations in the coastal ecosystem, and currently, over 9000 species are known worldwide [27]. Polychaetes are a major food source for invertebrates, fish, and birds. Polychaetes live by digging holes in the tidal flat, which facilitates material circulation within the tidal flat by transporting sediments deep in the tidal flat and helps organisms to live in various environments by supplying oxygen to the depth of the tidal flat [28]. Tubuca arcuata, the third most arthropod in this area, is a marine crustacean belonging to Family Ocypodidae. It lives by making a hole vertically in the muddy bottom of the upper and central parts of the intertidal zone of tidal flats and lives in the west and south seas. The depth of the hole made by Tubuca arcuata is approximately $60-80 \mathrm{~cm}$, and it comes out of the hole to feed when the ebb tide [29].

When looking at the frequency of appearance, most of the dominant species appeared at sites No. 2, 4, and 5. A relatively high habitat density of Austruca lactea was observed in the edge of the unused saltern of sites No. 1,2, and 5. Austruca lactea, which inhabits the upper intertidal zone of the tidal flat where sand and pearl are mixed, is a species very susceptible to the disruption and destruction of its habitat. It has been designated as an endangered wild species (Ministry of Environment) and marine protected organism (Ministry of Oceans and Fisheries) and is legally protected and managed. Thus, further studies on the exact distribution area and habitat environment within Yubu Island are required. In July, in the tidal flat of Yubu Island, the mean diversity index was found to be $1.20 \pm 0.55$, richness index was $1.57 \pm 0.79$, evenness index was $0.82 \pm 0.33$, and dominance index was $0.55 \pm 0.26$ (Table 5). Sites No. 8 and 4 had relatively high diversity and richness indices but a low dominance index. Since only one species of Macrophthalmus japonicus appeared at Site 6, the ecological index could not be identified. It has a similar diversity index when compared with the diversity index of the tidal flat of Hakseong and Boryeong in the summer $(1.37 \pm 0.49)$ [13].

Table 5. Ecological indices of macrobenthic information collected from the tidal flat of Yubu Island in the western coastal area of South Korea.

\begin{tabular}{ccccc}
\hline Site No. & Diversity(H') & Richness(R) & Evenness(J) & Dominance(D) \\
\hline 1 & 1.04 & 1.44 & 0.95 & 0.75 \\
2 & 1.48 & 2.06 & 0.92 & 0.57 \\
3 & 1.39 & 2.16 & 1.00 & 0.50 \\
4 & 1.68 & 2.28 & 0.94 & 0.56 \\
5 & 1.24 & 1.25 & 0.89 & 0.73 \\
6 & 0.00 & 0.00 & 0.00 & 0.00 \\
7 & 1.01 & 1.12 & 0.92 & 0.83 \\
8 & 1.74 & 2.28 & 0.97 & 0.44 \\
Mean \pm SD & $1.20 \pm 0.55$ & $1.57 \pm 0.79$ & $0.82 \pm 0.33$ & $0.55 \pm 0.26$ \\
\hline
\end{tabular}




\section{Conclusions}

This study investigated the environmental and topographic characteristics of the tidal flat of Yubu Island, as well as the composition of macrobenthos that inhabit the Yubu Island tidal flat through a survey in July 2017. In terms of the environmental characteristics, the Yubu Island tidal flat, which became an unused saltern 50 years ago, was similar to a marsh covered with sand with relatively little mud content. The concentration of TC and TN were $0.35 \%$ and $0.05 \%$, respectively. The analysis of $\delta^{13} \mathrm{C}$ values and TC:TN in sediments revealed that most of the sediments are oceanic in origin. As a result of measuring the sedimentation rate through the analysis of ${ }^{210} \mathrm{~Pb}$, it was found to be $0.99-1.66 \mathrm{~cm} \mathrm{yr}^{-1}$, which is higher than that of the nearby tidal flat of the Yellow Sea. This can be considered a result of the development of a sedimentary environment near Yubu Island as the currents in the north-south direction strengthened, and the flow of sea currents entering around Yubu Island weakened after the nearby Saemangeum 4 seawall construction was completed. Furthermore, the high sedimentation rate can also be interpreted as a result of the sedimentary change in the estuary due to the opening and closing of the sluice gate at the Geum River estuary. From the topographic survey, the total area of Yubu Island's unused saltern was found to be $289.489 \mathrm{~m}^{2}$, and the collapse of the southeastern embankment of the unused saltern can be considered an indirect result of the construction of the training dike near Yubu Island and the operation of the sluice gate at the Geum River estuary. Regarding the macrobenthos, which influences the energy flow and carbon cycle of the tidal flat ecosystem as secondary producers and a food source for predators, a total of 13 species were detected; the mean habitat density was 92 ind. $\mathrm{m}^{-2}$, and the mean biomass was $58.6 \mathrm{~g} \mathrm{~m}^{-2}$. The most dominant species was Heteromastus filiformis: 21 ind. $\mathrm{m}^{-2}, 23.1 \%$ ). This species was followed by Perinereis linea (18 ind. $\mathrm{m}^{-2}, 19.2 \%$ ) and Tubuca arcuata (16 ind. $\mathrm{m}^{-2}, 17.3 \%$ ). The data on the environment and macrobenthos obtained through this study can be used when considering projects for the Yubu Island tidal flat conservation and management in the future.

Supplementary Materials: The following are available online at https://www.mdpi.com/article/ $10.3390 / j m s e 9050455 / s 1$, Table S1. Environmental characteristics of the Yubu Island tidal flat in the western coastal area of the Yellow Sea of the South Korea.

Author Contributions: For research articles, H.S.K. organized the sampling and measured the chemical properties and benthos community, and H.K. analyzed the data and wrote the manuscript. All authors have read and agreed to the published version of the manuscript.

Funding: The National Marine Biodiversity Institute of Korea (2021M00300) and the Korea Institute of Ocean Science and Technology (E99912).

Institutional Review Board Statement: Not applicable.

Informed Consent Statement: Not applicable.

Data Availability Statement: The all data presented in this study are available.

Acknowledgments: This work was supported by a grant from the National Marine Biodiversity Institute of Korea (2021M00300) and the Korea Institute of Ocean Science and Technology's major research project, "Study on biogeochemical cycle and marine environment change (E99912)".

Conflicts of Interest: The authors declare no conflict of interest.

\section{References}

1. Lee, S.Y.; Choi, Y.S.; Joo, S.; Jeong, G.; You, Y.H. Foraging behavior and preys in relation to feeding site types of the Eurasian oystercatcher (Haematopus ostralegus osculans) during the breeding season in Yubu Island, Korea. Korean J. Ecol. Environ. 2018, 51, 184-191. [CrossRef]

2. Xu, Z.; Kim, D.J.; Kim, S.H. Research of topography changes by artificial structures and scattering mechanisms in Yoobu-Do inter-tidal flat using remote sensing data. Korean J. Remote Sens. 2013, 29, 57-68. [CrossRef]

3. Kwon, H.; Lee, S. Physical environment changes in the Keum River estuary by the dyke gate operation I. Mean sea level and tide. J. Korean Soc. Oceanogr. 1999, 4, 93-100. 
4. Baek, H.Y. Characteristics of Sea Level, Tidal and Sub-Tidal Current Variations in the Saemangeum Costal Area. Master's Thesis, Kunsan National University, Kunsan, Korea, 2008.

5. Lee, H.H.; Um, J.S. Water depth change caused by artificial structures in Geum River estuary: Spatio-temporal evaluation based on GIS. J. Korean Geol. Soc. 2007, 42, 121-132.

6. Ministry of Ocean and Fisheries. The Korean Standard Method for the Examination of Marine Environment, Part 2. Sediment; Marine Environment Management Act: Seoul, Korea, 2018; p. 142.

7. Kaufman, A.; Li, Y.H.; Turekian, K.K. The removal rates of 234Th and 228Th from waters of the New York Bight. Earth Planet. Sci. Lett. 1981, 54, 385-392. [CrossRef]

8. Pix4D. 2017. Available online: https:/ / www.pix4d.com (accessed on 1 August 2017).

9. Shannon, C.E.; Weaver, W.W. The Mathematical Theory of Communications; University of Illinois Press: Urbana, IL, USA, $1963 ;$ p. 117.

10. Margalef, R. Information Theory in Ecology. Gen. Syst. 1958, 3, 36-71.

11. Pielou, E.C. Ecological Diversity; John Wiley: New York, NY, USA, 1975; p. 165.

12. NcNaughton, S.J. Structure and function in California grasslands. Ecology 1968, 49, 962-972. [CrossRef]

13. Yang, D.W.; Lee, J.H.; Kim, H.; Bae, H.N.; Park, J.S.; Kim, H.S. Analysis of microbenthic community structure in an intertidal flat in Hakseong-ri, Boryeong, Korea. Sea 2021, under review.

14. Hwang, J.S. Radiocarbon for studies of organic matter cycling in the ocean. Sea 2012, 17, 189-201. [CrossRef]

15. Deines, P. The isotopic composition of reduced organic carbon. In Handbook of Environmental Isotope Geochemistry, The Terrestrial Environment, A, 1st ed.; Fritz, P., Fontes, J.C., Eds.; Elsevier: Amsterdam, The Netherlands, 1980; Volume 1, pp. $329-406$.

16. Thornton, S.F.; McManus, J. Application of organic carbon and nitrogen stable isotope and C/N ratios as Source indicators of organic matter provenance in estuarine system: Evidence from the estuary, Scotland. Estuar. Coast. Shelf S. 1994, 38, $219-233$. [CrossRef]

17. Stein, R. Accumulation of Organic Carbon in Marine Sediments, 1st ed.; Stein, R., Ed.; Springer: Berlin, Germany, $1991 ;$ pp. 1-217.

18. Kim, H.; Lee, K.; Lim, D.; Nam, S.I.; Kim, T.W.; Yang, J.Y.T.; Ko, Y.; Shin, K.H.; Lee, E. Widespread Anthropogenic Nitrogen in Northwestern Pacific Ocean Sediment. Environ. Sci. Tech. 2017, 51, 6044-6052. [CrossRef]

19. Alexander, C.R.; Nittrouer, C.A.; Demester, D.J.; Park, Y.A.; Park, S.D. Macrotidal mudflats of the southwestern Korean coast: A model for interpretation of intertidal deposits. J. Sediment. Petrol. 1991, 61, 805-824.

20. Warwick, R.M.; Ashman, C.M.; Brown, A.R.; Clarke, K.R.; Dowell, B.; Hart, B.; Lewis, R.E.; Shillabeer, N.; Somerfield, P.J.; Tapp, J.F. Inter-annual changes in the biodiversity and community structure of the macrobenthos in Tees Bay and the Tees estuary, UK, associated with local and regional environmental events. Mar. Ecol. Prog. Ser. 2002, 234, 1-13. [CrossRef]

21. Ysebaert, T.; Herman, P.M.J. Spatial and temporal variation in benthic macrofauna and relationships with environmental variables in an estuarine, intertidal soft-sediment environment. Mar. Ecol. Prog. Ser. 2002, 244, 105-124. [CrossRef]

22. Lee, H.J.; Ryu, J. Short-term variations in spatial distribution of the macrozoobenthic community near the Geum River estuary. Korea J. Korean Soc. Mar. Environ. Energy 2018, 21, 368-380. [CrossRef]

23. Jang, S.Y.; Shin, H.C. Differences in the community structures of macrobenthic polychaetes from farming grounds and natural habitats in Gamak bay. J. Korean Soc. Mar. Environ. Energy 2016, 19, 297-309. [CrossRef]

24. Ryu, J.; Khim, J.S.; Kang, S.J.; Kang, D.; Lee, C.H.; Koh, C.H. The impact of heavy metal pollution gradients in sediments on benthic macrofauna at population and community levels. Environ. Pollut. 2011, 159, 2622-2629. [CrossRef]

25. Tsutsumi, H.; Kikuchi, T.; Tanaka, M.; Higashi, T.; Imasaka, K.; Miyazaki, M. Benthic faunal succession in a cove organically polluted by fish farming. Mar. Pollut. Bull. 1991, 23, 233-238. [CrossRef]

26. Choi, H.K.; Yoon, S.M. First record of Heteromastus filiformis (Polychaeta: Capitellidae) from Korea water, with a taxonomic note on the geuns. J. Species Res. 2016, 5, 264-271. [CrossRef]

27. Morris, S.; Rouse, G.W.; Pleijel, F. Polychaetes. Geol. Mag. 2003, 140, 617-618. [CrossRef]

28. Pocklington, P.; Wells, P.G. Polychaetes Key taxa for marine environmental quality monitoring. Mar. Pollut. Bull. 1992, 24, 593-598. [CrossRef]

29. Murai, M. Courtship activity of wandering and burrow-holding male Uca arcuata, Ethology. Korean J. Ecol. Environ. 1992, $92,124-134$. 